\title{
La presencia sindical y las crisis en el Estado español: 1975-1985 y 2008-2015
}

\author{
David Moral Martín \\ Universitat Rovira i Virgili, Tarragona \\ josedavid.moral@urv.cat
}

Resumen: La actual inestabilidad política favorece la aparición tanto de partidarios de establecer cambios en el complejo sistema sociopolítico como de defensores a ultranza del modelo bajo el que se recuperó la democracia durante el último cuarto del siglo Xx. Estas disputas solo las podrán decantar las urnas. En la construcción del modelo cuestionado participaron las, por entonces, recién legalizadas centrales sindicales mayoritarias. Por ello, llama poderosamente la atención que estas centrales no bayan sido reclamadas por ninguno de los grupos que abogan por la revisión del modelo actual.

Al respecto, se analizará el papel que ha jugado el sindicalismo mayoritario en las transformaciones que han operado sobre el sistema español de relaciones laborales. Para ello, se estudiará el comportamiento del diálogo social en las dos grandes crisis que ha afrontado, y aún afronta, el Reino de España, al entenderlas como situaciones complejas en las que el recurso a la concertación ba permitido reflejar el poder y las estrategias de los que han intervenido. La primera tuvo lugar durante la década comprendida entre 1975 y 1985, durante la que se inició el modelo de corporativismo precarizador. En esta apuesta colaboró el sindicalismo de clase a través de la construcción del ente eficiente. Este modelo sindical, bajo graves pugnas internas, participó en los grandes pactos y acuerdos suscritos entre 1979 y 1984, tiempo en el que nació un sindicalismo institucional con una gran presencia sociopolítica. Estos pactos y acuerdos fueron luces que intentaron ocultar las sombras del fracaso que ha supuesto desde sus orígenes el diálogo social, como demuestra la pérdida de poder adquisitivo acumulada desde entonces.

La segunda crisis acaecida en España es la actual, en la que las centrales sindicales se han visto sometidas a numerosas presiones, internas y externas, que las ban 
llevado al limite en su planteamiento de intercambiar baja por alta precariedad. Esta situación explicaría, parcialmente, la dificultad que entraña la elección del modelo de acción sindical: ¿Habilitar espacios en la negociación colectiva para introducir la precarización «negociada» de las condiciones salariales y laborales, o ser consideradas institucionalmente como residuales? Esta complejidad se ve incrementada por la total orientación de los gobiernos españoles a satisfacer los mercados internacionales.

Prácticamente desde su constitución este drama se habia venido gestando $y$, en parte, explicaría la facilidad que encontraron los agentes financieros para fomentar la deuda de las familias al suministrarles el crédito necesario para poder soportar un consumo imposibilitado por la degradación del nivel de rentas, a las que históricamente, aunque con limitaciones, contribuyeron sus representantes sindicales. Ante tal fracaso, las organizaciones sindicales se encuentran sin apoyos en todos los ámbitos, surgen voces que exigen un cambio de modelo y se ensayan nuevas estrategias y nuevos agentes sindicales. El ejemplo más claro al respecto, que no el único, es el de Somos, sindicato que se encuentra a la sombra del fenómeno Podemos y que es un nuevo agente social que sitúa a la sociedad ante cuestiones necesarias por ser acuciantes: ¿Es posible generar una nueva conciencia de clase digital que sustituya a la industrial? ¿Es necesario un sindicato que asuma las contradicciones anteriores y que recoja el malestar para seguir participando en la nueva concertación?

Palabras clave: Reformas laborales, corporativismo, sindicatos, crisis y precariedad.

Abstract: The current unstable political situation causes both keen to establish changes in our complex socio-political system as proponent model under which recovered democracy during the last quarter of the twentieth century. Disputes only the polls decanted. In building the model involved the question, then, newly legalized unions majority. That is why it calls attention that the central cited have not been claimed by any of the groups favourable to the revision. In response analyse the role played by the majority unionism in the transformations that have been operating on the Spanish industrial relations System.

We studied the behavior of social dialogue in the two major crisis that has faced and still faces, the Kingdom of Spain, to understand such complex situations where the use of social dialogue allowed reflect the power and strategies of each of the participants. The first took place during the decade of 1975-1985, starting model "precarious corporatism». Bet on which he collaborated class unionism through the construction of «Ente Efficient». Union model, under severe infighting, participated in major accords and agreements signed between 1979 and 1984, an institutional unionism born with great socio-political presence. Lights trying to bide the shadows of failure that resulted from its origins social dialogue, as evidenced by the loss of purchasing power accumulated since. 
The second is the current crisis where unions have been subjected to numerous pressures, internal and external, that have led to the limit in its approach to exchange low for bighly precarious. This situation partly explains the difficulty of the choice of model of union action: to have spaces in collective bargaining to enter the «negotiated» precarious wages and working conditions or institutionally be considered as residual?. Complexity increased by the total orientation of Spanish governments towards meeting international markets.

Drama was causing for almost its constitution. Situation would explain, at least in part, ease encountered by financial agents to promote household debt by providing the necessary credit to support consumption prevented the degradation of the level of rents that historically albeit with limitations, contributed their union representatives. Failure that bas caused these faults supports, are in all areas. In response, voices calling for a paradigm shift arise assayed new strategies and union agents. In this case the clearest example that not alone, is the Somos, union lies in the shadow of the phenomenon Podemos. New social agent which brings us to issues necessary for pressing, is it possible to generate a new «digital class consciousness» one to replace industrial?, a union to assume the above contradictions and collect necessary discomfort to follow participating in the new agreement?

Keywords: Labor reforms, corporatism, unions, crisis and precariousness. 


\section{Introducción}

Se está a las puertas de un nuevo ciclo electoral definido por su incierto resultado: «el paisaje electoral presenta [...] un notable grado de labilidad y fluidez» (Toharia, 2015) ${ }^{1}$. Dicha situación parece conducir a la ruptura de «la indiscutible sucesión en el poder entre PP y PSOE» (Garea, 2015) ${ }^{2}$. De confirmarse este cambio, esto supondría la ruptura del actual reparto gubernamental, vigente desde las elecciones de $1982^{3}$, y la despedida del parlamentarismo moderno español configurado bajo la transición.

La fractura de la polaridad política viene acompañada, paradójicamente, de la dicotomía entre la conservación y la reforma del legado social y político de la transición o primera transición. Mientras unos - ¿Los que vienen?- la culpan de todos los males y abogan por «hacer la segunda transición» ${ }^{4}$ (Navarro, 2012), otros - ¿Los que se van? - le atribuyen todas las bondades posibles: «el marco en el que hemos podido construir un gran país $\aleph^{5}$ (Aznar, 2015). Colateralmente con el anterior debate, pueden afirmarse dos hechos. El primero es la asunción por parte de ambas posturas de la hegemonía del capitalismo financiero, pues se apuesta por reformas estructurales políticas en lugar de oponerse a este. La segunda es el olvido del movimiento obrero organizado, cuya presencia en esta segunda transición no se contempla en ninguno de sus planteamientos. ¿Puede que este olvido sea consecuencia de asumir el orden económico actual? En el presente artículo se reflexionará sobre cómo se ha llegado al aparente ostracismo sindical.

Para ello, se analizará, desde la vertiente del diálogo social, cuál ha sido el comportamiento de los sindicatos mayoritarios en las dos crisis económicas y sociales que más han marcado, y lo continúan haciendo en la actualidad, la reciente historia democrática del Reino de España. La primera crisis tuvo lugar en la década comprendida entre 1975 y 1985 . Fue un periodo que empezó con la concertación, gracias a la colaboración sindical del ente eficiente, y que acabó con el desencanto ante la evidente falta de reciprocidad. La segunda crisis, comprendida entre 2008 y 2015, cuyo final es difícil de pronosticar, supone el agudo

1 Tal y cómo lo indica Juán José Toharia en su reciente artículo, «¿Hacia el cuatripartidismo?». En <http:// www.metroscopia.org/images/destacados/cuatripartidismo.jpg>. Visitado el 12 de enero del 2015.

2 El País, «Un año cargado de elecciones y de incertidumbre». En <http://politica.elpais.com/politica/2015/01/01/actualidad/1420138690_967768.html>. Visitado el 2 de enero del 2015.

3 Ese mismo año, el PSOE llegó al poder, desalojó al anterior partido centrista e inició el final de la denominada transición española.

4 «La necesidad de una segunda transición». Disponible en: <http://www.ccoo-servicios.es >. Visitado el 15 de enero del 2015.

5 Declaraciones de José María Aznar en <http://www.abc.es/espana/20150216/abci-aznar-institutoatlantico-201502161330.html> y en <http://www.abc.es/espana/20150216/abci-aznar-instituto-atlantico-201502161330.htm > [consultado el 17/02/2015]. 
y profundo desgaste de estas organizaciones de trabajadores, tanto por su dureza como por cuestiones de gestión interna y externa, como los continuos capítulos de presunta corrupción y enriquecimiento personal de ciertos dirigentes ${ }^{6}$.

Para desarrollar estas ideas se estudiarán tres aspectos. Primero, se analizará la creación del corporativismo y del ente eficiente sindical. Segundo, se investigara el contexto socioeconómico bajo el que se produjo la primera crisis de la democracia. Y tercero, se examinará la participación de los sindicatos mayoritarios o más representativos en el contexto actual de crisis. Después de reflexionar sobre estos tres aspectos, se presentarán algunas conclusiones e interrogantes, a partir de los cuales se iniciarán investigaciones posteriores.

\section{La fortaleza del movimiento obrero predemocrático y los antecedentes de la primera crisis $₫$ el nacimiento del ente eficiente ${ }^{7}$}

Entre 1960 y 1973, en España se produjo una etapa de «intensa industrialización» (Ruiz Galacho, 2006: 8), lo que la colocó en una buena, e irreal, situación frente a la denominada crisis del petróleo, anunciada por Nixon el 15 de agosto de 1971 (Varoufakis, 2011). Este crecimiento favoreció la consolidación de un fuerte movimiento obrero, cuyas raíces se sitúan «a partir del segundo lustro de los cincuenta» (San Román, 2008: 130), que era capaz de cuestionar «todo el modelo de regulación del capitalismo industrial» (López y Rodríguez, 2010: 476). La aprobación de la Ley de Convenios Colectivos de $1958^{8}$, que posibilitó la negociación directa con las ilegalizadas centrales sindicales, fue un claro ejemplo.

La fortaleza sindical explicaría, al menos parcialmente, que en 1972 se llegara a un contexto de «conflicto total» (San Román, 2008), donde los salarios se incrementaron notablemente (Ruiz Galacho, 2006). La respuesta patronal no se hizo esperar a través de una doble coacción: por un lado, la represión estatal y, por otro, la espiral salarios-precios. Como reacción se produjeron nuevas demostraciones de la fuerza obrera: se provocó el fracaso de la política de rentas moderadas (1973-1975), que tomó «como referencia a la inflación precedente [... ]

6 «El secretario general de CC. OO., Ignacio Fernández Toxo, ha manifestado la necesidad de revisar numerosos aspectos del sindicato para adaptarlos a los cambios sociales y laborales, ya que "o se reinterpreta de forma constante o le llevará por delante los vientos de la historia"», en <http://economia.elpais.com/economia> [consultado el 4/02/2015].

7 Esta expresión fue utilizada en la comunicación «La creación del ente eficiente», que su autor presentó al XI Congreso de la FES: «Crisis y cambios: propuestas desde la sociología», celebrado en Madrid del 10 al 13 de julio de 2013.

8 Para conocer mejor la cuestión del neocorporativismo y la necesidad del catolicismo español de encontrar una fórmula corporativa «natural», hay que acudir a un texto, ya clásico: Martínez Alier, J. y Roca Jusmet, J. (1988): Economía politica del corporativismo en el Estado español: del franquismo al posfranquismo. 
más algunos puntos» (López y Rodríguez, 2010: 476); y se consiguió la promulgación de la Ley de Relaciones Laborales de abril de $1976^{9}$, posibilitando que «en plena crisis económica se formulara por vez primera en el Derecho del Trabajo español una norma legal explícitamente favorable a la contratación indefinida» (Ruiz Galacho, 2006: 9). Estos triunfos fueron posibles gracias a que «la movilización política y las demandas sindicales iban juntas» (Martínez Lucio, 2002: 551), situación que caracterizó el modelo sindical español, y no fue una cuestión menor al analizar la gran afiliación que se registró durante su primera fase legal.

Estas victorias reflejaron la imposibilidad de las autoridades públicas por controlar el poderoso movimiento obrero organizado, que propiciaba situaciones poco tranquilizadoras para un régimen totalitario, y un nuevo hecho vino a confirmarlo. En 1976, mientras se estaba celebrando la huelga de Vitoria se perpetró una gran matanza: «cinco trabajadores fueron asesinados y más de cien resultaron heridos $»^{10}$. Tras esta masacre, durante el resto del año, fueron convocadas varias huelgas en las que resultó evidente la ausencia de mediación sindical. Por ello, surgió una idea compartida: el ente eficiente sindical español (en adelante, EES), que permitiría el diálogo social y contaba con el apoyo del sindicalismo internacional más corporativo ${ }^{11}$ (Marín Arce, 1997). No obstante, era una idea difícil de materializar dada la atroz rivalidad sindical existente.

La construcción del EES comenzó a gestarse «tras los trágicos sucesos de Vitoria, con el fin de establecer un único organismo de toda la oposición» (Marín Arce, 1997: 41, nota 77), encarnándose en la Coordinadora de Organizaciones Sindicales ${ }^{12}$ (en adelante, COS), que fue erigida ante el «interés del PCE y del PSOE en consolidar en el ámbito sindical la unidad alcanzada por las fuerzas políticas de oposición», y de ahí que fuese formalmente organizada por «CC. OO., UGT y USO» (Marín Arce, 1996: 43). Como resultado final, a partir de 1977, «la estrategia sindical se desplazó hacia el compromiso y la concertación política nacional» (Martínez Lucio, 2002: 551).

\footnotetext{
9 Donde también se instauraron «vacaciones de 25 días al año, semana laboral de 44 horas, potenciación de los contratos indefinidos y práctica imposibilidad del despido libre» (San Román, 2008: 132).

$10 \ll \mathrm{J}-3$ a J-1. Dile a Salinas que hemos contribuido a la paliza más grande de la historia. Aquí ha habido una masacre. Cambio» (Guindal, 2013: 81).

11 Esta interpretación se basa en la subvención que recibió el sindicato UGT de la DGB (Confederación Alemana de Sindicatos), la CIOSL (Confederación Internacional de Organizaciones Sindicales Libres) y de los sindicatos suecos. Asimismo, debe tenerse en cuenta la poco clara intervención de la CIA, mediante la oscura figura del sindicalista americano Irving Brown. También contó con apoyo económico de la CFDT (Confederación Francesa Democrática de Trabajadores) y de la Federación de la Electricidad de la USO, abiertamente a favor de UGT. Si bien esta cuestión solamente se refleja en el presente texto, se apunta como un posible tema de investigación en un futuro próximo (Marín Arce, 1997).
}

12 La creación de la COS tuvo lugar a mediados de 1976 por las principales organizaciones sindicales: CC. OO., UGT y USO, y se disolvió a principios de 1977. 
El interés de los citados partidos políticos fue meramente estratégico y se basó en el reparto de las culpas asociadas a la colaboración corporativa entre todas las centrales sindicales participantes, con el objetivo de evitar la estigmatización de alguna de ellas bajo el sambenito de su participación. Este análisis justificaría el verdadero origen del interés de la unidad sindical, que no unicidade ${ }^{13}$. La tímida defensa que llevaron a cabo las centrales sindicales de la COS confirma su tacticismo. UGT la describió como «un organismo de unidad de acción destinado a precipitar la ruptura democrática y sindical». Para USO, significó «un instrumento muy válido para controlar el proceso de disolución de la CNS». Finalmente, CC. OO. la concibió como «un instrumento de unidad de acción en la perspectiva de la unidad sindical» (Marín Arce, 1997: 51, notas 114, 115 y 116).

La respuesta interna y la desafección obrera que produjo esta estrategia avalan el análisis efectuado en este artículo. Por un lado, se conoce el intento por revitalizar la alianza sindical ${ }^{14}$ desde Cataluña como modelo alternativo al de la COS, y por otro, la apuesta por la concertación (Aguilar, 1989) produjo «la caída de los niveles de afiliación sindical» (Martínez Lucio, 2002: 551), que fue especialmente aguda después de 1978. La desafección obrera fue simultánea a «una considerable participación en las elecciones a delegados y comités de empresa» (Martínez-Alier y Roca, 1988: 40), que mostraba claramente el desencanto con la apuesta sindical de participación o con los términos en los que se produjo.

Este importante cambio en la acción sindical necesitó de la construcción ad hoc de un nuevo lenguaje sindical (en adelante, NLS) con el que conjugar una compleja situación: establecer canales institucionales de interlocución social para evitar el incremento de la conflictividad laboral frente a un movimiento obrero radicalizado. El PCE se implicó a fondo en esta tarea al apostar por «articular un nuevo marco de relaciones laborales» y por «la formalización de agentes sindicales "legítimos" capaces de contener la espiral sindical» (López y Rodríguez, 2010: 223). El uso del NLS ayudó, según Etxerreta, a la transformación del sindicato en «el instrumento para que los trabajadores aceptaran la austeridad y no para canalizar sus reivindicaciones» $(1991$ : 410). Esta descripción la compartió, pero de forma matizada, Antón, que consideraba que el «movimiento sindical español a finales de los setenta [buscó la] institucionalización de los mecanismos de voz de los trabajadores» $(2006: 55)$.

$13 \mathrm{Al}$ estilo del sindicalismo revolucionario portugués tras la Revolución de los Claveles. La ruptura de la apuesta de la Intersindical portuguesa por la unicidade duró hasta 1978, cuando se fundó la UGT portuguesa con los militantes, «controlados pelos socialistas e pelos partidos à sua direita [del Partido Comunista Portugués] tendo como origem sindicatos não operários (banca, seguros, etc.)», en $\langle$ http://www.ugt.pt $>$ [consultado el 21/03/2015].

14 Unión de la CNT, el SOC y UGT (Marín Arce, 1977: 45). 
La puesta en marcha de la nueva estructura económica en España necesitó que el EES cumpliese con su tarea asignada. Las fechas nos muestran una concatenación casi arquitectónica. En abril de 1977 se legalizaron los sindicatos, junto con el $\mathrm{PCE}^{15}$. El 15 de junio se celebraron las primeras elecciones democráticas y en octubre de ese mismo año se firmaron los Pactos de la Moncloa. El 29 de diciembre de 1978 se publicó la Constitución española en el Boletín Oficial del Estado (BOE), así que se confirmó el principio de la institucionalización de los agentes sociales.

Esta «arquitectura cronológica» se agotó con la aprobación del otro pilar de las relaciones laborales modernas: el Estatuto de los Trabajadores de 1980. Las medidas aceptadas por el sindicalismo mayoritario redujeron la conflictividad laboral. Paradójicamente, una de estas medidas fue la institución del régimen anterior: las elecciones sindicales ${ }^{16}$, que era un instrumento «casi desconocido en el resto del mundo industrializado» (Ruiz Galacho, 2006) y que posibilitó «garantizar mecanismos legítimos de interlocución entre la parte laboral y la patronal» (López y Rodríguez, 2010: 223).

Una vez acabado el proceso anterior, el EES recogió sus frutos $: a)$ alcanzó el estatus de agente institucional, $b$ ) garantizó su monopolio sobre «la representación de los intereses de los trabajadores» (García Calavia, 2012:36) a través de un número mayor de votos (CC. OO. y UGT $)^{17}$, y c) empezó su conversión a un «sindicalismo de votantes (voter's trade unionism) en vez de un sindicalismo de afiliados (member's trade unionism)» (Martín Valverde, 1991: 24-25). ¿Estos frutos eran el «pago» político a cambio de la participación en la concertación? La aprobación de la Ley Orgánica de Libertad Sindical (LOLS) en 1985, que recogió el blindaje del «sindicato más representativo», quizá ayude a responder a esa pregunta. No obstante, cabe destacar que estas concesiones originaron gran parte de los problemas de las centrales sindicales más representativas en la actualidad.

15 Autores como San Román sitúan con anterioridad la participación de las organizaciones sindicales: «aprobada en referéndum la Ley para la Reforma Política a finales de 1976, CC. OO. y UGT se integraron en el proceso de transición a la democracia, y asumieron en este terreno la estrategia que marcaban los partidos con los que guardaban estrechos vínculos (con el PCE y el PSOE, respectivamente)» (2008: 135).

$16 \mathrm{La}$ influencia sindical mediante las elecciones ha ocultado durante años su verdadero problema: la pérdida de afiliación.

17 Se hace alusión al ámbito estatal en su conjunto, sin tener en cuenta las diferencias autonómicas, sobre todo el caso vasco. 


\section{La primera crisis: la década de la transición (1975- 1985) y el inicio del corporativismo. Los Pactos de la Moncloa}

Pérez Díaz describió la importancia de los Pactos de la Moncloa, al considerarlos como un «un intercambio de política antiinflacionista, [... a cambio de la moderación salarial (e implícitamente la moderación de la conflictividad)» (1986: xx). En la misma línea, López y Rodríguez concibieron estos pactos como «el documento fundante de la transición económica» (2010: 147). Por su parte, Pérez Domínguez (1994) resaltó su trascendencia para el diálogo social presentándolos como el inicio de la "práctica neocorporativa», punto en el que coincidió con Martínez-Alier y Roca, para quienes fue «el primer momento práctico importante del neocorporativismo franquista» (1998: 41). Los pactos no fueron firmados por las centrales sindicales por su «ínfima representación institucional», a pesar de convertirse en sus "principales valedores a la hora de contener [...] los crecimientos salariales» (López y Rodríguez, 2010: 223). Su participación posiblemente había sido diseñada con antelación, pues el ministro de Economía, Fuentes Quintana, ya había informado sobre el contenido de estos pactos en agosto de 1977.

La colaboración sindical significó legitimar el inicio de una táctica precarizadora de las condiciones de trabajo, lo que supuso, incluso, la modificación de los criterios para la revisión salarial ${ }^{18}$, tal como señaló Ruiz Galachoः «[la] subordinación de los aumentos salariales a la inflación prevista por el gobierno, en lugar de hacerlo sobre la inflación pasada» (2006: xx). Esto propició que se introdujera un elemento de imprevisibilidad y de subjetividad en la cuestión salarial, pues los datos previstos los ofrecía el Gobierno. Al respecto, debe tenerse en cuenta que en la crisis actual se está planteado que la revisión salarial se vincule al $\mathrm{PIB}^{19}$. Esta estrategia se completa con medidas de coacción hacia las citadas centrales sindicales en forma de despidos, pues las «demandas sindicales [se penalizarían] [...] con la reducción de plantilla de trabajadores en un 5 por ciento» (1996: 10).

Para justificar la participación sindical en estos pactos, se recurrió al NLS, rápidamente aprendido por sus actores. CC. OO. planteó como objetivo «sanear la economía para sanear la democracia», estrategia claramente vinculada al PCE

18 Para una visión sobre el impacto de esta crisis en la construcción del estado del bienestar español, véase Muñoz de Bustillo, R. (2008): La transición político-económica y la construcción del estado de bienestar en España (1975-1986).

19 «CC. OO. y UGT aceptan vincular el salario al PIB», en <http://www.lavanguardia.com> [consultado el 24/02/2015]. 
(Antón, 2006: 76). UGT, en $1978^{20}$, se resignó ante un "plan global de política económica que hoy por hoy no tiene alternativas viables» (García Becedas, 1983: 13). CNT se negó a participar en este proceso, a pesar de haber sido invitada, puesto que seguía vinculada al anterior lenguaje sindical. La pérdida de vigor en la actuación sindical ante la nueva situación, visible en su apuesta por los pactos, quedó perfectamente reflejada por Martínez-Alier y Roca, al entender que se orientaba «más en función de la voluntad de consolidación democrática que como respuesta sindical frente a la crisis» (1988: 37). Un ejemplo que avala esta aseveración es que se desarrollaron las medidas de los Pactos de la Moncloa de carácter económico, pero no las de tipo social.

Según Baylos, «las crisis económicas inducen tradicionalmente modificaciones importantes en la regulación jurídica de las relaciones de trabajo» (2010: 109). Se ha aprendido cómo los cambios van más allá. Con el final de la dictadura, España se abrió al resto del mundo, que en esos momentos padecía la crisis del petróleo. Las circunstancias que se estaban viviendo en 1977 «requerían una nueva política económica» (Carreras y Tafanell, 2010: 375), pues esta podría llevarse por delante la incipiente construcción democrática. Por ello, se optó por «políticas de pactos sociales y de intermediación de intereses entre organizaciones sindicales y patronales» (Fernández, 2011: 170).

El panorama económico enturbió también el político. Un reflejo de ello fue el débil gobierno que surgió tras las primeras elecciones democráticas de abril de 1979. En su contra se situaron dos fuerzas políticas de izquierda, el PCE y el PSOE, que a su vez, intentaban acabar el uno con el otro, al tiempo que se reformaban ideológicamente. El abandono del leninismo por parte del PCE y del marxismo por parte del PSOE en 1979 supuso una «condición sine qua non para su crecimiento» (Andrade, 2012: 325). Se llevó al terreno sindical esta lucha entre partidos, que había sido abandonada por una feroz competencia estratégica intersindical, resultado de sus diferentes modelos de acción. Frente al sindicalismo histórico de UGT, «más afín al [modelo] alemán» y proclive al pacto, CC. OO. se basaba en «los modelos italianos y francés» (Antón, 2006: 77). Esta dualidad se zanjó con las primeras elecciones sindicales, celebradas del 16 de enero al 6 de febrero de 1978, en las que se demostró la hegemonía de CC. OO.

Cada una de las centrales sindicales gestionó de forma diferente el resultado de estas elecciones. CC. OO. planteó la unidad sindical bajo un ambiente de enfrentamiento entre sindicatos y en pleno proceso de construcción corporativista. UGT rechazó su estrategia y argumentó en su XXXI Congreso que «el Gobierno ha pretendido potenciar a Comisiones Obreras» (García Beceda, 1983: 13).

20 Durante su XXXI Congreso, celebrado en Barcelona. 
La derrota sindical contribuyó a que UGT se plantease, bajo las directrices del PSOE, lograr la hegemonía sindical, otorgando «prioridad a la negociación y el acuerdo» (Antón, 2006: 77). Este nuevo tempo sindical se inició con la firma, en 1979, del Acuerdo Básico Interconfederal ${ }^{21}$ (ABI), firmado por la CEOE y UGT sin contar con CC. OO. Cabe destacar que este pacto fue auspiciado por un PSOE que pensaba en la alternancia política y en la necesidad de contar con un sindicato hermano. La firma consiguió «echar el ancla» al fijar el contenido del Estatuto de los Trabajadores y frenar así el texto planteado por CC. OO., cuya propuesta estatutaria se había recogido siguiendo el estilo del Código de Trabajo italiano $^{22}$.

\begin{tabular}{|c|c|c|c|c|}
\hline \multicolumn{5}{|c|}{$\begin{array}{c}\text { Resultados de las elecciones «sindicales" } \\
\text { (Porcentaje de representantes de cada sindicato respecto al total de delegados } \\
\text { y miembros de comités de empresa) }\end{array}$} \\
\hline & 1978 & 1980 & 1982 & 1986 \\
\hline $\mathrm{CC} . \mathrm{OO}, \ldots \ldots \ldots \ldots \ldots \ldots \ldots$ & & 30.86 & 33,40 & 3427 \\
\hline 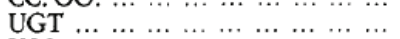 & $\begin{array}{l}74,4) \\
21,69\end{array}$ & $\begin{array}{l}39,27 \\
29,27\end{array}$ & 36,71 & $\begin{array}{l}7,27 \\
40,19\end{array}$ \\
\hline 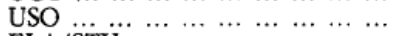 & 3,87 & 8,68 & 4,64 & 3,83 \\
\hline $\begin{array}{llllllll}\mathrm{ELA} / \mathrm{STV} & \ldots & \ldots & \ldots & \ldots & \ldots & \ldots & \ldots\end{array}$ & 1,00 & 2,44 & 3,30 & 2,92 \\
\hline 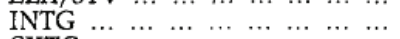 & - & 1,01 & 1,17 & 0,63 \\
\hline $\begin{array}{lllllllll}\text { CXTG } & \ldots & \ldots & \ldots & \ldots & \ldots & \ldots & \ldots & \ldots\end{array}$ & - & - & - & 0,62 \\
\hline $\begin{array}{llllllll}\text { Otros } & \ldots & \ldots & \ldots & \ldots & \ldots & \ldots & \ldots\end{array}$ & 20,85 & 11,94 & 8,69 & 9,95 \\
\hline $\begin{array}{lllllll}\text { No afiliados } & \ldots & \ldots & \ldots & \ldots & \ldots & \ldots\end{array}$ & 18,12 & 15,77 & 12,09 & 7,60 \\
\hline
\end{tabular}

Fuente: Martínez-Alier y Roca (1988: 40)

En 1980, UGT firmó, junto con la patronal, el Acuerdo Marco Interconfederal (AMI), «ratificado más adelante por la Unión Sindical Obrera». Este acuerdo favoreció que la patronal introdujera más medidas de precarización ${ }^{23}$ : «el descuelgue para las empresas con pérdidas, y reglas sobre productividad y absentismo» (Antón, 2006: 77). Además, «la tendencia de UGT a tomar posiciones en la hegemonía sindical» (Rubio, 1986: 215-217) fue apoyada por la patronal al poner en marcha «una política destinada a favorecer a UGT». En paralelo, UGT puso «en práctica una táctica desmovilizadora, desconvocando las acciones que promovía CC. OO.» (Etzerreta, 1991: 411).

Hasta tal punto la obtención de la hegemonía sindical fue prioritaria para UGT que convocó un congreso extraordinario ${ }^{24}$ para «ofrecer a la CEOE garan-

21 Sin apenas haber transcurrido un año tras la firma de los Pactos de la Moncloa.

22 Un proyecto que fue presentado ante las Cortes, en octubre de 1977, por mediación del PCE.

23 Sumada junto con la moderación salarial iniciada con los Pactos de la Moncloa.

24 Celebrado entre los días 14 y 15 de diciembre de 1979. 
tías formales suficientes de que el AMI [...] [sería] íntegra y escrupulosamente cumplido»(García Becedas, 1983: 18). La respuesta de CC. OO. debe analizarse teniendo en cuenta el impacto que supuso el resultado de las elecciones sindicales de 1980. Su aparente triunfo ${ }^{25}$ demostró tanto su escasa ventaja sobre UGT como la crítica subyacente a su modelo de acción sindical, por lo que se diseñaron dos maniobras: la ruptura, por un lado, con «la estrategia de UGT no restringiendo las movilizaciones al marco de la negociación convenio a convenio» (Etzerreta, 1991: 412) y, por otro, con el aislamiento sindical a través de la colaboración en el diálogo social, pues mientras UGT firmaba convenios basados en pequeños aumentos salariales por la paz social, «la mayoría de los sindicalistas de CC. OO. se quedaban fuera» (Etzerreta, 1991:411).

Este cambio significativo se justificó recurriendo, de nuevo, al NLS y asumiendo como propio el análisis de la «salida compartida de la crisis», que había propuesto el PCE. A partir de entonces, CC. OO. intervino bajo unas reglas de juego que no le fueron propicias, como se demuestra en la pérdida de las elecciones sindicales de 1982 .

La aprobación del Estatuto de los Trabajadores (en adelante, ET) se inició bajo la firma bilateral del ABI y, posteriormente, del AMI por parte de UGT y de la patronal. El ET se aprobó en marzo de 1980, recogiendo aspectos planteados por CC. OO, como «la consolidación de los comités de empresa y el protagonismo de los sindicatos mayoritarios como interlocutores del gobierno y la patronal». Esta aprobación debe contextualizarse, además, en un entorno internacional complejo, en el que se trataba de «conseguir en España en muy pocos años lo que en el mundo occidental se [había] conseguido en un tiempo más largo» (Etzerreta, 1991:438), es decir, su inclusión en el orden neoliberal.

Esta norma favoreció dos grandes transformaciones sobre el mercado de trabajo. La primera consistió en menguar la capacidad de presión de los trabajadores: «la resistencia de los núcleos obreros más combativos no fue repentinamente vencida, pero sí eficazmente aislada» (López y Rodríguez; 2010: 148). Con la segunda gran transformación se institucionalizó «el nuevo entorno de las relaciones laborales» (Pérez Domínguez, 1994: 279), que estaba basado en la negociación de grandes acuerdos de carácter precarizador, en los que se intercambiaba reducción de conflictividad por incremento de presencia política. No es de extrañar, por tanto, que esta ley produjese una gran satisfacción en la patronal, puesto que asumió sus condiciones de flexibilización y abandonó la idea del pleno empleo para refugiarse en el concepto de fomento de la contratación. En cambio,

25 Debe recordarse que CC. OO. perdió las elecciones en las grandes empresas, núcleo del sindicalismo de clase, frente a UGT. Este hecho auguraba una victoria posterior del sindicato socialdemócrata, tal como se produjo en 1982, coincidiendo con el acceso al poder del PSOE. 
las centrales sindicales se mostraron menos complacientes. Por un lado, UGT no se sintió apoyada en su lucha contra su gran rival y, por otro, CC. OO. ${ }^{26}$ vio cómo las relaciones laborales se situaron en un terreno abonado para un modelo sindical germánico.

Tras la aprobación del ET y durante el bienio 1982-1984, se constató el cambio de acción sindical de CC. OO., que fue firmando pactos y acuerdos tripartitos hasta 1984, año en el que el Gobierno rompió esta inercia, tal como describió Rubio (1986: 215 y 216):

[...] el Acuerdo Nacional de Empleo (ANE) es firmado por el GobiernoCEOE-sindicatos para su aplicación en 1982. [...] El intento de firma de un Acuerdo Interconfederal para 1984 falla, lo que motiva que el Gobierno tome la iniciativa en 1984 para la firma del Acuerdo Económico y Social (AES).

Esta aseveración la compartió Pérez Infante (2009: 44):

[... el ANE lo suscriben, por primera vez, el gobierno y todas las organizaciones sindicales y empresariales más representativas a nivel estatal, $[\ldots]$ y el AI lo firman los agentes sociales, UGT, CC. OO. y CEOE, sin participación del gobierno.

De este diálogo social, el sindicato sacó más provecho en el terreno institucional que en el económico. Así, se logró un amplio reconocimiento y una amplia protección de su papel institucional: «los sindicatos y la patronal adquirieron una jerarquía "oficial" [...] y un protagonismo esencial en la configuración de las políticas macroeconómicas en los pactos sociales» (Fernández, 2011: 171). Esta incorporación al orden social no resultó gratuita, lo que permitió a Pérez Díaz hablar de cierta «domesticación sindical»: «siempre es posible darles a cambio ayudas económicas directas o indirectas [...], o bien otorgar puestos de influencia en el aparato estatal o paraestatal a sus líderes y sus militantes» (1986: xx), palabras que hoy nos deben parecer premonitorias. A cambio se consiguió cierta «expansión relativa del gasto público [...] muy por debajo de los estándares de la OCDE y de la Comunidad Europea» (López y Rodríguez, 2010) y puede que un incremento del empleo público.

26 Una visión que desde la «periferia» vasca se vivió de una manera menos bipolar: «el año 1979, se presenta el proyecto de ley del Estatuto de los Trabajadores, fruto de un acuerdo entre UGT y CEOE que obviando la realidad sindical quiere entregar el protagonismo de las relaciones laborales a UGT y neutralizar el sindicalismo vasco de ELA. La importante contestación a esta imposición supuso las primeras movilizaciones y manifestaciones masivas del movimiento obrero vasco a la vuelta de la clandestinidad», en <www.mrafundazioa.org/ sobre-ela/historia-1> [consultado el 12/02/2015]. 


\section{Las reformas laborales durante la crisis actual}

A continuación, se analizará el comportamiento del sindicalismo y del diálogo social durante la crisis actual a fin de explicar cómo ha perdido relevancia. No debe olvidarse que se considera que para salir de la crisis y conseguir una la «recuperación real y sostenible, es preciso conciliar los objetivos macroeconómicos y los objetivos de empleo» (OIT, 2014: v).

Se parte de la constatación de la existencia de un diálogo social estable y de unas reglas institucionales laborales firmes, que son las bases sobre las que asentar una adecuada redistribución de riqueza por la vía pública (prestaciones/ beneficios sociales) o la vía privada (salarios). La Fundación $1 .^{\circ}$ de Mayo ha conseguido demostrar con números la inestabilidad institucional del sistema de relaciones laborales y la amenaza que ello supone para el diálogo social. Desde 1980 hasta $2014^{27}$, «se han producido en España hasta 52 reformas del Estatuto de los Trabajadores» (Fundación 1. ${ }^{\circ}$ de Mayo, 2014:6), la mayoría de estas, 34 en total, se produjeron durante el periodo comprendido entre 2012 y 2014, coincidiendo con el retroceso en el ámbito del diálogo social. Así pues, ‘hablamos de reparto de riqueza o de servilismo a los mercados ${ }^{28}$ ?

Todas estas reformas fueron de gran envergadura. Cruz Villalón las situó al nivel de las de «1984 [... y 2002» (2010: 23) y Morata y Díaz las equipararon a la «acometida en 1994 y la operada en el trienio 2010-2011-2012» (2013: 46). Ante un modelo laboral tan poco sólido, el legislador buscó fórmulas de éxito, acercándose al «modelo neoliberal anglosajón» (Martín-Artiles, 2014: 5). ¿Por qué ese espejo? Sin duda, porque «las empresas españolas tienen un tamaño medio que se sitúa cerca del $75 \%$ del tamaño promedio de la UE», básicamente son pymes. El Reino Unido ha conseguido que «el $6 \%$ de las empresas del Reino Unido que registraron un mayor crecimiento entre 2002 y 2008 (unas 11.530 empresas, todas mayores de 10 trabajadores) generó el $54 \%$ de los nuevos puestos de trabajo» (Xifrè, 2014: 11 y 16). Estos datos sobre la capacidad de creación de empleo de las pymes británicas son sorprendentes y avalan el fomento del acercamiento al modelo anglosajón.

27 «España ha hecho tres reformas laborales en cinco años y la Comisión que usted preside las pone como ejemplo día tras día, a pesar de que el paro es del $23 \%$, y el desempleo juvenil supera el $50 \%$, entrevista al presidente de la Comisión Europea. <http://internacional.elpais.com/internacional/2015/03/03/actualidad> [consultado el 7/03/2015].

28 Nuestra sensación se basa en una total desorientación y en una improvisación continua, objeto de intentar agradar a los múltiples agente internacionales, financieros y políticos, pendientes de nuestras macro y micro cifras económicas. 
Los datos anteriores demuestran que existe una clara intencionalidad por reconstruir el mercado de trabajo ${ }^{29}$ favoreciendo la precarización del sistema de relaciones laborales ${ }^{30}$, sin aparentes contraprestaciones sindicales, como consecuencia de la anorexia afiliativo-institucional que padecen los sindicatos. Cabe destacar que las citadas reformas plantean una inquietante reflexión: «¿Solo mientras dure la crisis?» (Morata y Díaz, 2013: 69). Para responder a esta pregunta, debe acudirse al análisis sobre el papel que ha tenido el diálogo social en las últimas reformas laborales aprobadas.

Es evidente que «since 2008, the EU is living the so-called financial crisis», crisis de la que han sido culpadas las instituciones financieras, no sin fundados motivos. Este análisis ha favorecido que se olvide una explicación más doméstica, directamente asociada al comportamiento sindical en el diálogo social, es decir, al progresivo encarecimiento de la cesta de la compra ${ }^{31}$, proceso vinculado con la pérdida de poder adquisitivo. Esto nos retrotrae hasta el origen del modelo institucional laboral moderno y su apuesta por la moderación salarial dialogada, a través del EES, losa de la que no parece que puedan desprenderse las actuales centrales sindicales.

Baylos y Trillo ahondaron en la relación existente entre el diálogo social y la cuestión distributiva: «since 2003, the main reason of these rates of poverty has to be found in incomes distribution inequality especially affecting the peripheral European countries» (2011 y 2013: 56). El Instituto Europeo Sindical culpó de ello a las reformas: «these labour law reforms and flexibilisation is the explosive growth of inequalities and insecurity» (2012: 16). En este sentido, la pregunta lógica es la siguiente: ¿Cómo actuaron las centrales sindicales españolas, concretamente las mayoritarias, tras constatar históricamente que el diálogo social había garantizado el empobrecimiento y la desigualdad? Al menos se sabe que su mirada estuvo «desenfocada». Un estudio de la Fundación $1{ }^{\circ}$ de Mayo ${ }^{32}$ explicó

29 Resulta, ciertamente, muy aventurado plantear lo siguiente, pues puede ser considerado como una simple especulación. Se entiende que la extensión de la falta, o ausencia, de diálogo social en casi todos los aspectos referidos al gobierno del PP, excepto en algún que otro gran acuerdo, plantea la íntima convicción de que lograr sacar a España de la crisis internacional más dura sufrida en toda su historia, les garantizaría el poder durante varias legislaturas, al menos hasta que se produjera el relevo generacional. Esto explicaría tanto el afán de gestionar la crisis por sí mismos, asumiendo todo el desgaste que supone dicho cometido, como la relativamente alta estabilidad del Gobierno, con tan solo una dimisión en su andadura por el momento.

30 El término precarización se sigue interpretando tal como lo definieron Fernández, Garrido y Toharia: «la creciente importancia del empleo temporal en el conjunto del empleo asalariado» (1995: 74).

31 Si bien en la actualidad la combinación de intereses bajos y la bajada del precio del crudo han permitido que el IPC haya retrocedido algo. En el momento de escribir, «la tasa de variación anual del IPC en el mes de enero es del $-1,3 \%$, tres décimas por debajo de la registrada el mes anterior», en <http://www.ine.es/daco/daco42/ daco421/ipc0115.pdf> [consultado el 15/03/2015].

32 «Bruno Estrada, Rodolfo Benito, Ignacio Fernández Toxo y Fernando Rocha, en la presentación del informe en la sede de CC. OO. de Madrid». Alguno de los nombres de los presentadores del informe no hacía presagiar nada bueno para el sindicalismo. Disponible en <http://www.1mayo.ccoo.es > [consultado el 14/03/2015]. 
las causas de la crisis, matizando el papel de las habituales ${ }^{33}$ en la economía española: «las propias debilidades del patrón de crecimiento en España [...] y el elevado endeudamiento de las empresas y familias» (2009: 9). No obstante, en este estudio no se identificó el papel menguante de la distribución salarial, que obligó a comprar a crédito, ni su pérdida de peso en el reparto empresarial ${ }^{34}$. En definitiva, este análisis no contesta a la pregunta clave siguiente: ¿Por qué tuvimos que recurrir al crédito para consumir todo tipo de bienes?

A continuación, se analizará el papel del diálogo social en la primera recesión. En ella, se produjeron dos claros comportamientos. Entre 2008 y 2010, se adoptaron planes de incentivos con «una participación significativa de los interlocutores sociales» (OIT, 2014: 152). En julio de 2008 se suscribió la «Declaración para el impulso de la economía, el empleo, la competitividad y el progreso social, documento propuesto por el Gobierno como "hoja de ruta" para el diálogo social en su segunda legislatura» (Luque, 2012: 257). Se recogieron propuestas orientadas a promover medidas paliativas, pero sin aportar medidas alternativas. Finalmente, hacia finales de 2009, se logró camuflar el cambio de estrategia bajo cierta intencionalidad: «el Gobierno resuelve iniciar un proceso específico de concertación social enderezado a abordar una reforma legislativa del marco laboral» (Cruz Villalón, 2010: 26).

La primera señal del abandono del diálogo social pudo observarse en la coincidencia de esta llamada con las reuniones existentes entre agentes sociales ${ }^{35}$, en la que se elaboró el «Acuerdo Interconfederal de Negociación Colectiva» ${ }^{36}$. La segunda señal, aún más clara, fue la derogación del anterior acuerdo, «en 2010 el Gobierno adoptó la reforma de modo unilateral» (OIT, 2014: 154). La tercera vino precedida de numerosas dudas acerca de la buena fe negociadora, al intuirse una doble estrategia: por un lado, la negociación relajada con los agentes sociales, ejemplificada mediante la entrega de una serie de documentos con contenidos fijados de antemano, concretamente tres ${ }^{37}$, que garantizó provocar la «ausencia

33 «Habituales» hace referencia a la clásica identificación de las causas de la crisis: «the crash of 2008 is based on the collapse of the subprime mortgages and the lack of financial market regulation» (Baylos, 2013: 56).

34 «Los salarios siguen perdiendo peso en la economía a favor de los beneficios de las empresas», en <http:// www.eldiario.es/economia/salarios-perdiendo-economia-beneficios-empresas > [consultado el 1/07/2014].

$35 \mathrm{La}$ patronal intentó reducir el ratio empresa por convenio (tipo de ratio referido a la proliferación o atomización de los convenios). A mayor ratio, menor atomización. Este ratio fue «en 2007 igual a 235, cifra similar a la de los años inmediatamente anteriores (2000-2006) y a la de la década de los ochenta del siglo pasado (1983-1990)» (Pérez Infante, 2010: 3).

36 Se publicó en el BOE el 22 de febrero de 2010.

37 «Líneas de actuación en el mercado de trabajo para su discusión con los interlocutores sociales en el marco del diálogo social ( 5 de febrero de 2010), diálogo social: sobre actuaciones en el mercado de trabajo (12 de abril de 2010) y borrador de medidas sobre el mercado de trabajo (11 de junio de 2010)» (Cruz Villalón, 2010: 26-27). 
de respaldo a las propuestas gubernamentales» (Cruz Villalón, 2010: 27); y por otro lado, los intensos contactos con los restantes grupos parlamentarios. Ante el fracaso previsible, el Gobierno aprobó el Real Decreto Ley 10/2010 (García Serrano, 2011: 167). Para su posterior tramitación como Ley 35/2010, necesitó el apoyo de los partidos de la oposición. Esta ley se aprobó con 173 votos a favor, 8 votos en contra y 168 abstenciones. De este modo, se demostró que tras el diálogo social se había ocultado otra negociación.

Para explicar por qué se mantuvo este aparente diálogo social deben tenerse en consideración dos circunstancias. La primera es que al inicio «de la crisis de la deuda soberana» se conservó cierta inercia negociadora, pero a partir de entonces, esta «declinó de forma considerable» (OIT, 2014: 152). La segunda es que la aprobación de la reforma anterior debe entenderse como el aprovechamiento de un compromiso para instaurar «una importante intervención sobre el sistema de relaciones laborales» (Segalés, 2011: 84), bajo el mantra de la «flexiguridad» ${ }^{38}$. Esto explicaría la necesidad tanto de utilización del diálogo social como de su finalización sin acuerdos, instrumentalizando el sindicalismo.

La respuesta frente a esta reforma fue una huelga general, la del 29 de septiembre. Con posterioridad, el 2 de febrero de 2011, se firmó el único acuerdo tripartito de la crisis, el Acuerdo Social y Económico para el Crecimiento, el Empleo y la Garantía de las Pensiones ${ }^{39}$ (ASE). El secretario general de UGT situó este acuerdo en su justo lugar: «el 2 de febrero no se puede entender sin el 29 de septiembre ${ }^{40}$. Sin embargo, el diálogo social fue sacrificado en aras del envío de señales a los mercados. El Real Decreto Ley 7/2011, recurrido por inconstitucionalidad al carecer de carácter de urgencia (Górriz y otros, 2011), fue bien acogido por los mercados internacionales.

\section{El fin del diálogo social concertado y el nacimiento de un nuevo diálogo social}

Tras el triunfo democrático del PP, nada hacía prever que la citada instrumentalización se reparase. Amparados bajo la segunda recesión, se aprobó una nueva reforma laboral. La novedad consistió en que esta vez no se recurrió al diálogo social, lo que provocó un efecto radical, truncando «una experiencia de concerta-

$38 \mathrm{Al}$ transcribir la palabra, en referencia al sistema español de relaciones laborales, debería escribirse del siguiente modo: FLEXIguridad. Así podría dejarse bien claro dónde reside tanto la fortaleza, como la hegemonía en el interior de esta palabra.

39 La falta de acuerdo en la negociación del ACE entre la patronal y los sindicatos, hizo que el Gobierno aprobase el Real Decreto Ley 7/2011, de 10 de junio, de medidas urgentes para la reforma de la negociación colectiva.

40 Disponible en La Factoría [en línea], 53, enero-febrero de 2011 [consultado el 1/03/2015]. 
ción afianzada durante largas décadas» (Cruz Villalón, 2010: 29), una legislación de carácter continuista, si bien adecuada a las exigencias laborales de la nueva recesión. González Ortega lo manifestó muy explícitamente: «el Real Decreto-Ley 3/2012 [... es sólo una etapa más del proceso de reformas» (2012: 86). Baylos y Trillo describen esta reforma como limitadora: «efforts to maintain and create jobs have been restricted to revising the regulation of labour relations» (2013: 58). Morata y Díaz entendieron que se trataba de culpar del desempleo «a la normativa que ordena el modelo de relaciones laborales» (2013: 43).

Estas reformas laborales, sin diálogo social, no han logrado mejorar el nivel de vida de la población. El índice Gini ${ }^{41}$ nos muestra un empeoramiento general entre 2009 y 2013, hecho contrastado por la OIT: «in Spain, real wages have contracted in almost all sectors since 2011» (OIT, 2015ः34).

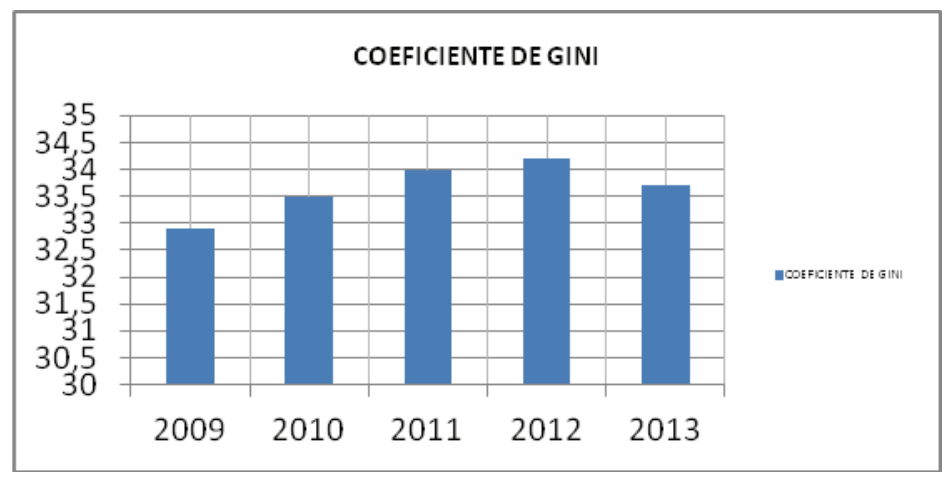

Fuente: Realización propia. Datos extraídos de <http://datos.bancomundial.org $>$

Marx hizo célebre el adagio "primero como tragedia, luego como farsa», que parece describir ciertas similitudes entre los dos últimos gobiernos estatales: socialistas y populares. A fin de demostrar esta afirmación, se hará alusión a los cambios introducidos en la negociación colectiva. Tras lo ocurrido con el anterior Gobierno, los agentes sociales volvieron a firmar un nuevo documento, el «Segundo Acuerdo para el Empleo y la Negociación Colectiva 2012-2014» (Rodríguez-Piñero, 2012). El objetivo era negociar en convenio la mejora de la flexibilidad interna, así como propiciar medidas de reestructuración. ¿Farsa o tragedia? El Gobierno del PP «estimó que el acuerdo bipartito no era suficiente», por lo que «adoptó la reforma de modo unilateral»(OIT, 2014: 154).

41 El índice de Gini mide hasta qué punto la distribución del ingreso entre individuos u hogares dentro de una economía se aleja de una distribución perfectamente equitativa (0) o totalmente inequitativa (100). 
Esto demuestra que dos gobiernos de signo opuesto partieron del mismo diagnóstico: «la dualidad del mercado laboral entre contratos temporales e indefinidos $[\ldots]$ y $[\ldots]$ la falta de flexibilidad interna y salarial de las empresas» (García Serrano, 2011: 163). Este análisis plantea tres conclusiones. La primera es que las actuaciones de ambos gobiernos se basaron en la «re-mercantilización del trabajo y de la primacía del orden neoliberal que propicia toda crisis» (MartínArtiles, 2014: 3). La segunda se entiende como la «necesidad sindical» por negociar la misma en los convenios, aunque en ningún caso se justifica el hecho del intercambio de alta por baja precariedad. La tercera es la necesidad de cambiar la estructura de la negociación colectiva en España.

En relación con esta última conclusión, Morata y Díaz nos recuerdan que «hasta este año [2013] el $80 \%$ de los trabajadores se encontraban en el ámbito subjetivo de aplicación de un convenio colectivo supraempresarial - provincial—» (2013: 47), por lo que la descentralización de la negociación colectiva resulta «acorde con las prácticas de las economías más neoliberales» (MartínArtiles, 2014:3-4), acercando el poder negociador a las posturas del empresariado e introduciendo a sus acreedores financieros internacionales en las mesas de negociación colectiva sin violentar la legislación ${ }^{42}$.

\section{Estructura de la negociación colectiva.}

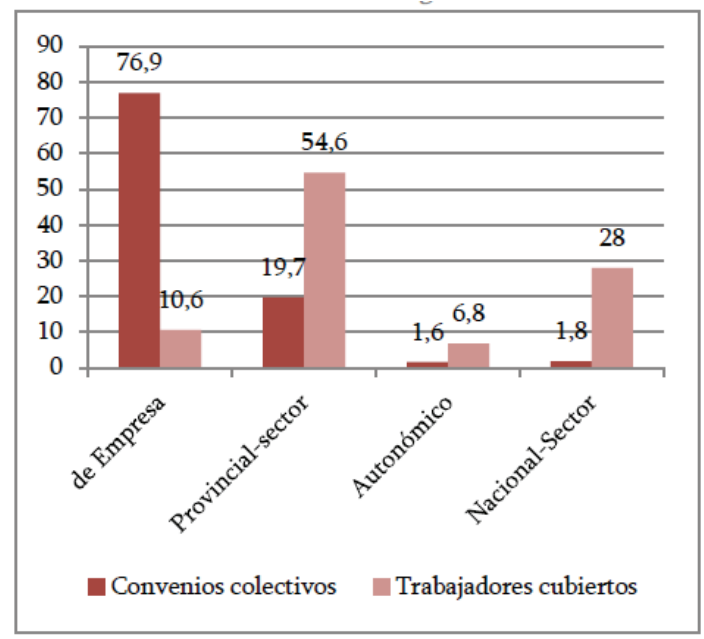

Fuente: Martín-Artiles, 2014: 13.

42 La defensa por una negociación colectiva descentralizada como solución a los problemas del mercado de trabajo resulta muy discutible, tal como se ha planteado. Sin embargo, se han esgrimido argumentos para su defensa desde la teoría del «marco de regulación institucional» (García de Polavieja, 2006). 
Para finalizar, la contestación sindical consistió en la convocatoria de dos huelgas generales estatales y la denuncia ante «el Comité de Libertad Sindical de la OIT» (OIT, 2014: 156) de la Ley 20/2012. La primera huelga general, el 29 de marzo, se convocó contra la «nefasta reforma de febrero de 2012» (Fundación $1 .^{\circ}$ de Mayo, 2014: 31). La segunda, conocida como la buelga general ibérica, fue seguida en varios países de la Unión Europea ${ }^{43}$. En relación con la denuncia internacional, la respuesta fue la esperada. La OIT observó dos carencias: la primera era la necesidad de «consultar con suficiente antelación a las organizaciones de trabajadores y de empleadores [... ] sobre los proyectos de ley y de Real Decretoley antes de aprobarlos»; y la segunda, la importancia de la concertación, «que las reglas esenciales [...] fueran compartidas en la mayor medida posible por las organizaciones de trabajadores y de empleadores más representativas» (OIT, 2014: 156).

\section{Conclusiones}

Las reformas laborales casi han prescindido del diálogo social y se ha constatado que ni han impedido la pérdida salarial directa ni han conseguido incrementar los ingresos indirectos. Por el contrario, han ayudado a aumentar la pobreza y la desigualdad social. Este hecho, al menos parcialmente, explicaría las distancias ideológico-materiales (escasa afiliación), emocionales (dudas ético-morales sobre comportamientos individuales y colectivos) y de acción (rechazo a la concertación institucionalizada) que mantiene con los trabajadores. La estrategia de participar en el sistema para conseguir rebajar la precariedad ha resultado nefasta. Esta incapacidad manifiesta a la hora de mantener el nivel adquisitivo ha sido aprovechada por el capital financiero para «secuestrar» las economías domésticas a base de crédito, lo que unido a la peor crisis conocida hasta el momento da la impresión de que ha contribuido a considerar «innecesaria» la presencia sindical, tal como parece desprenderse del análisis de las reformas aprobadas desde 2010. No se sabe hasta dónde llegará este comportamiento: ¿Hasta Italia? ¿Se parará en Francia?

Estas cuestiones ponen en duda el futuro del modelo institucional sindical, ya que los sindicatos mayoritarios corren el serio riesgo de convertirse en residuales ante la pérdida masiva de apoyos ${ }^{44}$. Esta situación es utilizada, cuando no provo-

43 Como símbolo, no debe olvidarse la agresión que sufrió una participante en la protesta de Barcelona, Esther Quintana, por la que perdió un ojo al impactar en su globo ocular una pelota de goma que, probablemente, fue disparada por algún agente del cuerpo de los Mossos d'Esquadra.

44 La posibilidad de perder los fondos de formación es la última de las actuaciones antisindicales del Gobierno del PP. La llamada realizada por el secretario general de CC. OO. entre reinterpretación o desaparición, parece ir en esta línea de análisis. 
cada, por ciertos poderes económicos, que están interesados en acomodar a los representantes del capital financiarizado en la negociación colectiva, sin vulnerar su legislación, pero aprovechándose de su descentralización. En este contexto de «amenazas», se constata que cada día son más las voces que claman por la superación del actual modelo de sindicalismo mayoritario, apareciendo nuevas fórmulas mágico-organizativas de trabajadores.

Para finalizar, se proponen una serie de cuestiones como base para futuras investigaciones. ¿Es Somos la salvación sindical-populista del actual modelo sindical? Esta organización plantea cuestiones radicalmente novedosas. ¿Estamos asistiendo a la creación de una «conciencia de clase digital» $\square$ que, basada sobre similares condiciones de explotación en términos del capitalismo actual, puede sustituir a la clásica surgida con el industrialismo? Esta apuesta sindical plantea dos situaciones interesantes: por un lado, ¿̀son Somos u otras propuestas similares el nuevo ente eficiente que asumirá el orden económico financiarizado a cambio de recibir la afiliación de sindicalistas y trabajadores indignados?; y por otro, el hecho de que la «casta» sustituya a los empleadores, ¿no debería interpretarse como la creación de un NLS? 


\section{Bibliografía}

Aguilar Fernández, S. (1989): «Neocorporativismo: origen del debate y principales tendencias», Politica y Sociedad, 3, pp. 57-62.

Antón, A. (2006): El devenir del sindicalismo y la cuestión juvenil, Madrid: Talasa.

Baylos Grau, A.y Trillo Párraga, A. (2013)ः «Social dimension of European union and the situation of the labor law in the member states: evaluation of the Spanish experience», Revista de Evaluación de Programas y Politicas Públicas, 1, pp. 54-71.

Baylos Grau, A. (2010): «Crisis, modelo europeo y reforma laboral», Anuario de la Facultad de Derecho de la Universidad Autónoma de Madrid, 14, pp. 109-120.

Cruz Villalón, J. (2010): «Algunas claves de la reforma laboral de 2010», Temas laborales: Revista andaluza de trabajo y bienestar social, 107, pp. 21-52.

Etzerreta, M. (1991): La reestructuración del capitalismo en España: 19701990, Barcelona: Icaria.

Fernández, F; Garrido, L., y Toharia, L. (1995): «Empleo y paro en España, 1976-1990», en C. Prieto Rodríguez y F. Miguélez Lobo (coords.) (1995): Las relaciones laborales en España, Madrid: Siglo XXI, pp. 43-96.

Martínez Lucio, M. (2002): «España: la regulación de la fragmentación laboral y social», en A. Ferner y R. Hyman (coords.) (2002): La transformación de las relaciones laborales en Europa, Madrid: Ministerio de Trabajo y Asuntos Sociales.

Fundación I. ${ }^{\circ}$ De Mayo (2014): «Febrero 2012-2014. 34 reformas laborales. Análisis de su alcance y efectos: menos ocupación, más desempleo, más precariedad laboral», Informe 77.

- (2009): «Reflexiones y propuestas para el cambio de modelo productivo en España», Informe 13.

García Becedas, G. (1983): «Sindicatos y patronales en el bienio 1978-1979», Revista de Política Social, 139, pp.7-51.

García Calavia, M. Á. (2012): Relaciones laborales en Europa Occidental, Valencia: Tirant lo Blanch.

García de Polavieja, J. (2006): «¿Por qué es tan alta la tasa de empleo temporal?: España en perspectiva comparada», REIS: Revista Española de Investigaciones Sociológicas, 113, pp. 77-105.

García Serrano, C. (2011): «¿Déjà Vu? Crisis de empleo y reformas laborales en España», Revista de Economía Aplicada, vol. 19 (56), pp. 149-177. 
Garea, F. (2015): «Un año cargado de elecciones y de incertidumbre», El País [en línea]. <http://politica.elpais.com/politica/2015/01/01/actualidad/1420138690_967768.html> [consultado el 2/01/2015].

González Ortega, S. (2012): «La negociación colectiva en el Real DecretoLey de medidas urgentes para la reforma del mercado laboral», Temas Laborales: Revista Andaluza de Trabajo y Bienestar Social, 115, pp. 85-134.

Guindal, M. (2013): El declive de los dioses, Barcelona: Planeta.

López, I. y Rodríguez, E. (2010): Fin de ciclo: financiarización, territorio y sociedad de propietarios en la onda larga del capitalismo bispano (1959-2010), Madrid: Traficantes de Sueños.

Luque Balbona, D. (2012): «La forma de las huelgas en España, 1905-2010», Politica y Sociedad, 50 (1), pp. 235-268.

Marín Arce, J. M. (1997): Los sindicatos y la reconversión industrial durante la transición, Madrid. Consejo Económico y Social.

- (1996): «La Coordinadora de Organizaciones Sindicales (COS): una experiencia de unidad de acción sindical durante la transición», Espacio, Tiempo y Forma, serie v, historia contemporánea, 9, pp. 295-314.

Martínez Alier, J. y Roca Jusmet, J. (1988): «Economía política del corporativismo en el Estado español: del franquismo al posfranquismo», Revista Española de Investigaciones Sociológicas, 41, pp. 25-62.

Martín-Artiles, A. (2014): «Presentación. Transformaciones recientes en el modelo de relaciones laborales», Anuario IET de Trabajo y Relaciones Laborales, 2, pp. 1-26.

Martín Valverde, A. (1991): «European employment and industrial relations glossary: Spain», Luxemburgo: Oficina de Publicaciones Oficiales de la Comunidades Europeas.

Morata García de la Puerta, B. y Díaz Aznarte, M. T. (2013): «Reforma laboral en España: precariedad, desigualdad social y funcionamiento del mercado de trabajo», Revista Estudios Socio-Jurídicos, 15 (2), pp. 41-71.

Muñoz de Bustillo Llorente, R. (2008): «La transición político-económica y la construcción del estado del bienestar en España (1975-1986)», Foro de Educación, 10 (ejemplar dedicado a la transición española (1975-1982)), pp. $11-22$.

Navarro, V. (2012): «La necesidad de una segunda transición», en los actos de graduación de licenciatura de los estudiantes de la Facultad de Derecho de la Universidad de Barcelona. <http://www.ccoo-servicios.es> [consultado el 15/01/2015]. 
Organización Internacional del Trabajo (OIT) (2015): «World employment and social outlook: trends 2015», Ginebra: OIT.

- (2014)ः «España‡ crecimiento con empleo», Ginebraः OIT.

Pérez Díaz, V+ (1986): «El retorno de la sociedad civil», Papeles de Economía Española, 27, pp. 99-121.

Pérez Domínguez, C. A. (1994): «El sistema de relaciones laborales en España: una revisión de la historia reciente», Anales de Estudios Económicos y Empresariales, 9, pp. 273-292.

Pérez Infante, J. I. (2010)ः «La negociación colectiva y los salarios en España: características y propuestas de reforma», pp. 1-45. Disponible en <http:// portal.ugt.org $>$.

- (2009): «La concentración y el diálogo social en España: 1977-2007», Revista del Ministerio de Trabajo e Inmigración, 81, pp. 41-70.

Rubio Castro, A. M. (1986): «El neocorporativismo español: El Acuerdo Económico y Social (1985-1986)», Revista de Estudios Políticos, 50, pp. 213240.

Rodríguez-Piñero Royo, M. C. (2012)ः «El II Acuerdo para el empleo y la negociación colectiva 2012-2014», Temas Laborales: Revista Andaluza de Trabajo y Bienestar Social, 115, pp. 55-84.

Ruiz Galacho, E. (2006): «Las reformas laborales en España (1977-2002)», Revista Laberinto, 20, pp. 7-22.

Segalés Fidalgo, J. (2011)ः «La reforma laboral 2010», Pertsonak eta Antolakunde Publikoak Kudeatzeko Euskal Aldizkaria, Revista Vasca de Gestión de Personas y Organizaciones Públicas, 1, pp. 83-96.

Subirats i Humet, J. (2013): «Internet y participación política: ¿Nueva política?, ¿nuevos actores?», Revista de Ciencias Sociales, 33 (ejemplar dedicado a las desigualdades y a las oportunidades en la sociedad del conocimiento), pp. 55-72.

Toharia, J. J. (2015)ः «Hacia el cuatripartidismo?», El País [en línea]. <http:// www.metroscopia.org/images/destacados/cuatripartidismo.jpg $>$ [consultado el 12/01/2015].

Varoufakis, Y. (2011): El minotauro global, Salamanca: Capitan Swing. 